九州大学学術情報リポジトリ

Kyushu University Institutional Repository

\title{
Herbicidal Activity and Mode of Action of Streptomyces scopuliridis Metabolites
}

Won, 0k Jae

Department of Crop Science, Chungnam National University

Kim, Young Tae

Department of Crop Science, Chungnam National University

Choi, Jung Sup

Eco-friendly and New Materials Research Group, Korea Research Institute of Chemical Technology

Oh, Taek-Keun

Department of Bio-Environmental Chemistry, Chungnam National University

他

https://doi.org/10.5109/1564081

出版情報：九州大学大学院農学研究院紀要. 61 (1)，pp.47-51，2016-02-29. Faculty of Agriculture， Kyushu University

バージョン :

権利関係 : 


\title{
Herbicidal Activity and Mode of Action of Streptomyces scopuliridis Metabolites
}

\author{
Ok Jae WON ${ }^{1}$, Young Tae KIM${ }^{1}$, Jung Sup CHOI' ${ }^{2}$ Taek-Keun OH$^{3}$, \\ Yoshiyuki SHINOGI and Kee Woong PARK ${ }^{1 *}$
}

\author{
Department of Bioproduction Environmental Sciences, Faculty of Agriculture, Kyushu University, \\ Hakozaki 6-10-1 Higashi-Ku, Fukuoka City 812-8581, Japan \\ (Received November 11, 2015 and accepted November 19, 2015)
}

\begin{abstract}
This study was conducted to examine the effects and the mode of action of a natural herbicidal substance, Streptomyces scopuliridis metabolites (SSM), which consists of herbicidin A and herbicidin B, derived from Streptomyces scopuliridis. Necrosis of Echinochloa oryzoides, Digitaria ciliaris, Abutilon theophrasti and Amaranthus retroflexus occurred within 3 days of SSM application at the concentration of 4,000 ppm. Symptoms of herbicidal action of SSM started to show soon following application, and appeared earlier than those caused by glyphosate but later than those caused by paraquat. Overall, herbicidal action of SSM appeared with a time interval similar to glufosinate ammonium following foliar application. Chlorophyll fluorescence level (Fv/Fm) was not affected by SSM application suggesting that SSM application did not inhibit photosynthesis of the treated plants. The amount of electrolyte leakage caused by SSM increased steadily with time, and was proportional to the concentration of SSM. Electrolyte leakage induced by paraquat occurred more rapidly than by SSM. No signs of translocation of SSM in a downward direction through the phloem was observed in either $D$. ciliaris or $A$. theophrasti. Based on the results from this study, the mode of action of SSM involves the rapid disruption of cell membrane caused by an unknown mechanism other than inhibition of photosynthesis. In the future, SSM would be a good candidate for a contact herbicide; however, a better understanding of its mode of action has to precede attempts for commercial development and practical application.
\end{abstract}

Key words: Natural herbicide, herbicidin, mode of action, Streptomyces scopuliridis

\section{INTRODUCTION}

It is a worldwide trend to reduce the use of organosynthetic herbicides. For example, regulations were introduced on chemical herbicides to reduce production by 40\% in OECD member countries until 2013 (Kim, 2009). Accordingly, in place of agricultural chemicals, natural herbicides have been developed using various bioactive substances originated from plants, animals, microorganisms and minerals. These natural herbicides have the advantage of reducing adverse effects on the natural environment because most of natural herbicidal molecules can be degraded easily by enzymes from microorganisms (Sekizawa, 1982).

Many natural herbicidal compounds are secreted by microorganisms such as fungi and bacteria, including actinomyces species. The actinomycetes are members of a large group of gram positive soil bacteria that are often filamentous in their structure (Joseph et al., 2012). Especially, Streptomyces spp. of actinomycetes produce $45 \%$ of antibiotics that have been developed (Umezawa

\footnotetext{
1 Department of Crop Science, Chungnam National University, Daejeon 34134, Korea

2 Eco-friendly and New Materials Research Group, Korea Research Institute of Chemical Technology, P.O. Box 107, 141, Gajeong-ro, Yuseong-gu, Daejeon, 34114, Korea

3 Department of Bio-Environmental Chemistry, Chungnam National University, Daejeon 34134, Korea

* Corresponding author (E-mail: parkkw@cnu.ac.kr) (K.W.
} Park) et al., 1982). These Streptomyces spp. have been very useful not only for the production of antibiotics, such as streptomycin isolated from S. griceus (Schatz et al., 1944), but also for the production of herbicidal compounds, such as bialaphos discovered from $S$. hygroscopicus (Tachibana and Kaneko, 1986). As only less than 10 percent of all bacteria are estimated to be culturable, many undiscovered microorganisms could potentially become a rich source of diverse bioactive compounds that could be exploited in various fields (Iwai and Takahashi 1992).

Several herbicidal compounds were reported to have been discovered from secondary metabolites of microorganisms, such as herbicidin A and B from S. saganonensis (Arai et al., 1976), homoalanosine from $S$. galilaeus (Fushimi et al., 1989), phosalachin from Kitasatospora phosalacinea (Omura et al., 1984) and hydantocidin from S. hygroscopicus (Nakajima et al., 1991). Glufosinate-ammonium and bialaphos were commercialized as nonselective herbicides based on actinomycetes compounds derived from S. hygroscopicus in 1984 and in 1986, respectively. The mode of action of both glufosinate-ammonium and bialaphos is the inhibition of glutamine synthesis inducing the accumulation of ammonia, which causes yellowing and withering of susceptible plants by suppressing photosynthesis (Tachibana and Kaneko, 1986; Ebert et al., 1990).

In Korea, methoxyhygromycin (MHM) was discovered from Streptomyces species (Lee et al., 2003) while nucleoside herbicides, herbicidin A and B, were found from $S$. scopuliridis. Especially, effective growth inhibi- 
tions of plants were observed when the herbicidal metabolites from S. scopuliridis (SSM) were applied on soil and foliage. These results suggested that the compounds extracted from microorganisms have potential for natural herbicides (Lee et al., 2013).

Growth of a monocotyledon weed, Echinochloa crus-galli, was reported to be suppressed 50-95\% by herbicidin A at a concentration of 300 ppm and suppressed $80-95 \%$ by herbicidin B at the same concentration (Arai et al., 1976). Dicotyledon weeds, Commelina communis, Portulaca oleracea and Chenopodium album, showed 100\% inhibition of growth by herbicidin $\mathrm{A}$ and $\mathrm{B}$ at a concentration of $300 \mathrm{ppm}$, respectively. By taking advantage of these characteristics, it may be possible to develop herbicidins as non-selective herbicides that can control broad-leaved weeds in fields (Arai et al., 1976). Nucleoside herbicides, herbicidin $\mathrm{A}\left(\mathrm{C}_{23} \mathrm{H}_{29}\right.$ $\left.\mathrm{N}_{5} \mathrm{O}_{11}, \mathrm{MW} 551.5 \mathrm{~g} / \mathrm{mol}\right)$ and $\mathrm{B}\left(\mathrm{C}_{18} \mathrm{H}_{23} \mathrm{~N}_{5} \mathrm{O}_{9}\right.$, MW $453.4 \mathrm{~g} /$ $\mathrm{mol})$, are composed of the same backbone that has a tricyclic furano-pyrano-pyran structure with internal hemiketal linkage to form a trans-junction for a pyranopyran ring (Choi et al., 2014). Although the chemical structures of herbicidins are well-known, their mode of action to suppress plants has not been fully understood.

In this study, herbicidal activity of SSM, a metabolite from $S$. scopuliridis, was assessed in a variety of weeds following foliage treatment and compared to a few other common chemical herbicides to evaluate its potential as a new natural nonselective herbicide. The reaction speed and effect of SSM were also assessed in comparison to those of other commercial herbicides. Results from this study will provide fundamental knowledge to understand the mode of action of the new herbicidal metabolite.

\section{MATERIALS AND METHODS}

\section{Herbicidal Metabolites}

SSM was discovered from soil actinobacteria $S$. scopuliridis (KCTC 12156BT) by Korea Research Institute of Chemical Technology. SSM used in this study is a crude extract from $S$. scopuliridis and consists of herbicidin A (50\%, w/w) and herbicidin B (5\%, w/w) (Lee et al., 2013).

\section{Assessment of Herbicidal Activity}

Herbicidal activity of SSM was examined on monocotyledon weeds, Echinochloa oryzoides and Digitaria ciliaris, and dicotyledon weeds, Abutilon theophrasti and Amaranthus retroflexus. SSM at 4,000 ppm mixed with DOS $70(0.2 \%)$ was applied at a rate of $1,000 l \mathrm{ha}^{-1}$ on the weeds at the two leaves stage. Seeds were sown separately into $105-$ hole seed propagation trays in a greenhouse under $30 \pm 5^{\circ} \mathrm{C}$. Three to five plants were grown from each hole for two weeks by bottom watering until treatment. Aboveground parts of weeds were collected one week after application and dry weights of collected samples were measured after drying at $720^{\circ} \mathrm{C}$ for $72 \mathrm{hr}$. Herbicidal activity of SSM was expressed as the percent of untreated control (dry weight of aboveground plant parts of treated plants compared to that of untreated plants). All treatments were triplicated.

\section{Time-Course Experiment of Herbicidal Activity of SSM}

SSM at 4,000 ppm with DOS $70(0.2 \%)$, commercial herbicides, glyphosate (Keunsami, 3,280 g a.i. ha ${ }^{-1}$ ), glufosinate ammonium (Basta, 1,440 g a.i. ha ${ }^{-1}$ ) and paraquat (Keuramoxon, $1,155 \mathrm{~g}$ a.i. $\mathrm{ha}^{-1}$ ) were applied on each of E. oryzoides, D. ciliaris, A. theophrasti and A. retroflexus. The plants were grown in 105-hole seed propagation trays until the plants were at the two or three leaf stage. Each commercial herbicide was applied following manufacturer's recommendations. Total fresh weight of each plant was measured every day for one week and expressed as the percent of untreated control (fresh weight of aboveground parts of treated plants compared to that of untreated plants).

\section{Mode of Action}

Assessment of Photosynthesis Inhibition

D. ciliaris was grown from seeds in pots $(6 \mathrm{~cm} \times$ $9 \mathrm{~cm}$ ) for two weeks in a greenhouse under $30 \pm 5^{\circ} \mathrm{C}$. SSM at 2,000 ppm with Tween 20 (0.2\%) and photosynthesis inhibitor hexazinone $\left(2,500 \mathrm{~g}\right.$ a.i. $\left.\mathrm{ha}^{-1}\right)$ were applied to the plant at the two or three leaf stage. After application, the treated plants were moved to a growth chamber under $30^{\circ} \mathrm{C} /$ day for $12 \mathrm{hr}$ and $25^{\circ} \mathrm{C} /$ night for $12 \mathrm{hr}$. Inhibition rate of photosynthesis was measured by a chlorophyll fluorometer (Handy PEA, Hansatech Instruments, UK) at 1, 2, 3, 6, 12 and $24 \mathrm{hr}$ after application.

\section{Electrolyte Leakage Assay}

An electrolyte leakage assay was performed with one week old Cucumis sativus seedlings. A total of 50 leaf discs (5 mm in diameter) were placed in a petri dish (60× $15 \mathrm{~mm}$ ) containing $1 \mathrm{mM}$ of MES buffer solution ( $\mathrm{pH}$ 6.5 ), and $7 \mathrm{ml}$ of SSM (500 ppm) or paraquat (1,155 g a.i. $\mathrm{ha}^{-1}$ ) was added to the petri dish. Untreated control was prepared in the same way as the treated ones except it received $7 \mathrm{ml}$ of water and all treatments were triplicated. Following treatment, the petri dishes were placed in a growth chamber under $28^{\circ} \mathrm{C} /$ day for incubation. Electrolyte leakage was measured at 0, 2, 4, 6, 8, 10 and 24 hours after application using an electronic conductivity meter (TOA-DKKCM-21P, DKK TOA, Japan).

In a separate experiment, electrolyte leakage was measured in the leaf tissue following application of SSM at different doses. Leaf discs were collected as described above. A total of 50 leaf discs were placed in a petri dish $(60 \times 15 \mathrm{~mm})$ containing $1 \mathrm{mM}$ of MES buffer solution (pH 6.5), and $7 \mathrm{ml}$ of SSM at 125,500 or 2,000 ppm was added to the petri dish. Untreated control received $7 \mathrm{ml}$ of water and each treatment was triplicated. Following treatment, the petri dishes were placed in a growth chamber under $28^{\circ} \mathrm{C} /$ day for incubation. Electrolyte leakage was measured at 0, 2, 4, 6, 8, 10 and 24 hours after application. 


\section{Examination of herbicidal symptoms and translo- cation}

$D$. ciliaris and $A$. theophrast $i$ were grown in a green house before application. When plants were at the three leaf stage, SSM at 4,000 ppm mixed with DOS 70 (0.2\%) was applied with a brush in circular shape on the middle of the second leaf. Herbicidal symptoms and translocation of SSM was examined one day after application and compared with untreated control.

\section{RESULTS AND DISCUSSION}

\section{Herbicidal activity of SSM}

SSM effectively controlled all weeds tested in this study within a week after application at 4,000 ppm (Table 1). This result corresponded to the results reported from another study (Lee et al., 2013), where 95-100\% control was achieved when an ethyl-acetate fraction from culture of $S$. scopuliridis was applied at a concentration of $1,000-2,000 \mu \mathrm{g} \mathrm{ml}^{-1}$. Treated plants started to show signs of the herbicidal action of SSM immediately following application. Excellent level of control of the weeds was achieved within 2 days after application. Within 4 days after SSM application, all treated weeds were nearly killed by desiccation. In comparison to the commercial herbicides, herbicidal action of SSM was more rapid than that of glyphosate but slower than that

Table 1. Herbicidal activity of Streptomyces scopuliridis metabolites (SSM) on weeds

\begin{tabular}{lc}
\hline \multicolumn{1}{c}{ Weed species } & $\begin{array}{c}\text { Herbicidal activity (\%) } \\
\text { of SSM (4,000 ppm) }\end{array}$ \\
\hline Echinochloa oryzoides & $99.2 \pm 4.1$ \\
Digitaria ciliaris & $99.1 \pm 2.1$ \\
Abutilon theophrasti & $97.3 \pm 6.5$ \\
Amaranthus retroflexus & $99.8 \pm 0.7$ \\
\hline
\end{tabular}

Mean \pm Standard Error

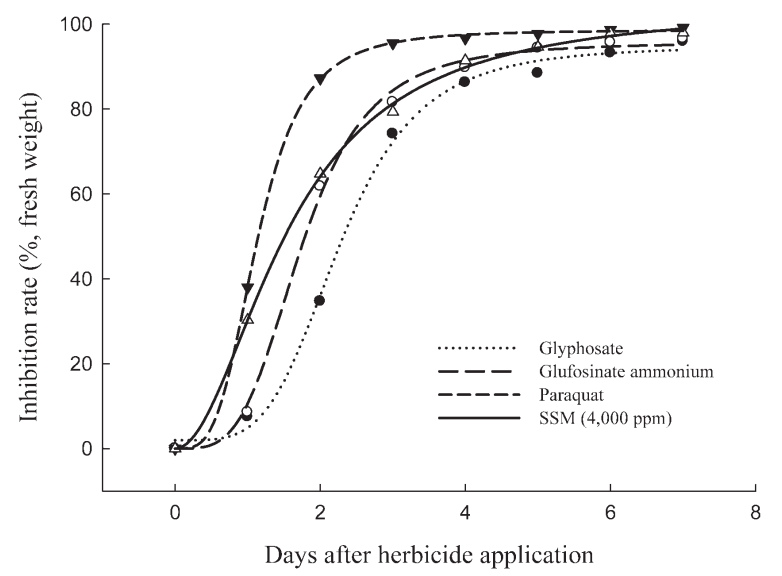

Fig. 1. Comparison of overall reaction speed between Streptomyces scopuliridis metabolites (SSM), and nonselective herbicides on Echinochloa oryzoides, Digitaria ciliaris, Abutilon theophrasti and Amaranthus retroflexus. of paraquat. Overall, herbicidal action of SSM, as shown in Fig. 1, occurred similarly to that of glufosinate ammonium, which effectively desiccated the plants in 48 hours and killed them in 72 hours (Lee, 2007). This observation was also similar to the result from another study, where cultured broth of $S$. scopuliridis caused withered death of plants in 3 days (Lee et al., 2007). Herbicidal activity of SSM to $A$. retroflexus was stronger than that of other commercial herbicides. The herbicidal action occurred at a similar time as that observed in the leaves of $A$. theophrasti but more slowly than that observed in the stem of $A$. theophrasti.

\section{Mode of Action}

\section{Inhibition of Photosynthesis}

Photosynthesis inhibitor herbicides suppress lightdependent reactions and electron transport systems in chloroplasts, which leads to accumulation of active oxygen, followed by oxidation of cell membranes and subsequent necrosis (Anderson, 1996). The inhibition rate of photosynthesis by photosynthesis inhibitor hexazinone and SSM was examined with a chlorophyll fluorometer. It was observed that the Fv/Fm value decreased to less than half of the initial value at 1 hour after hexazinone treatment and was zero at 6 hours after treatment (Fig. 2). This result corresponds to results of a study by Preston, 1991, where paraquat induced fast decrease of Fv/Fm value in Conyza bonariensis (Preston, 1991). However, in our study, there was no change of $\mathrm{Fv} / \mathrm{Fm}$ value after SSM treatment. On the basis of this result, it was assumed that SSM did not inhibit photosynthesis.

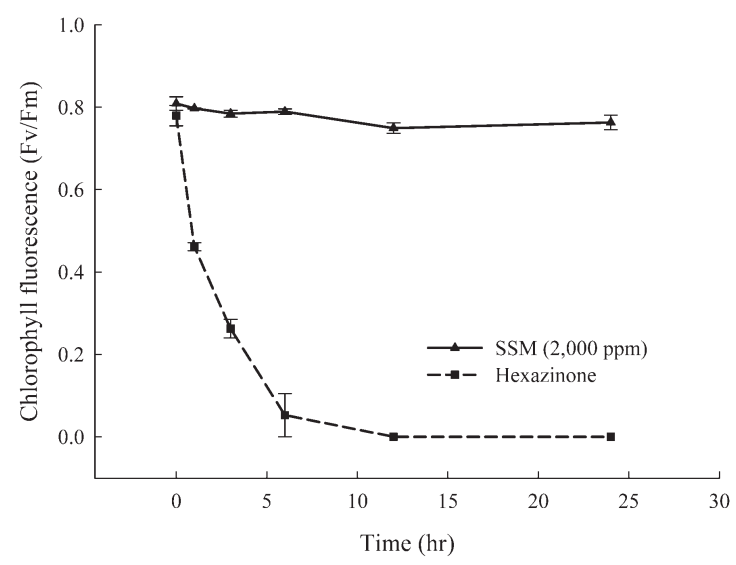

Fig. 2. Inhibition rate of photosynthesis in Digitaria ciliaris between by Streptomyces scopuliridis metabolites (SSM), and hexazinone.

\section{Electrolyte Leakage}

An electrolyte leakage assay was performed to examine whether herbicidal activity of SSM resulted from the disruption of cell membranes or not. As shown in Fig. 3, electrolyte leakage occurred rapidly from 2 to 8 hours after paraquat treatment $\left(1,155 \mathrm{~g}\right.$ a.i. $\left.\mathrm{ha}^{-1}\right)$ whereas it occurred more slowly after treatment with SSM (500 ppm). The pattern of electrolyte leakage in Nicotiana 


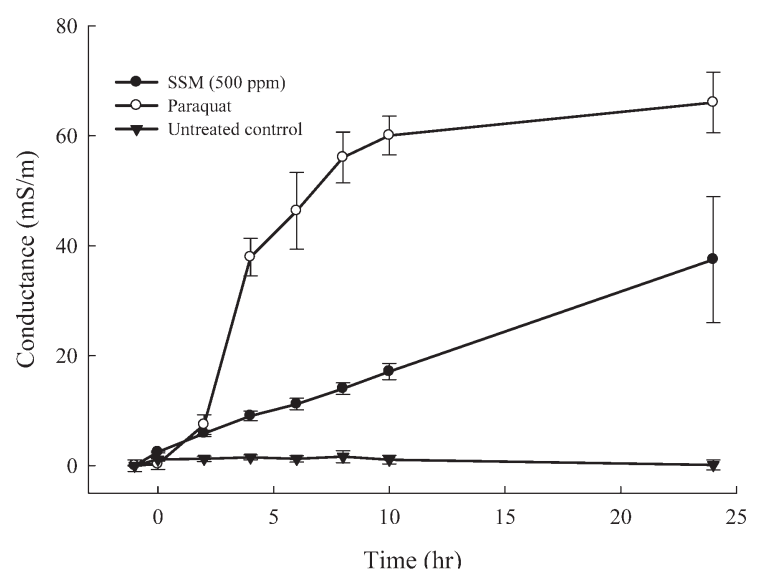

Fig. 3. Comparison of electrolyte leakage in Cucumis sativus between by Streptomyces scopuliridis metabolites (SSM) and paraquat.

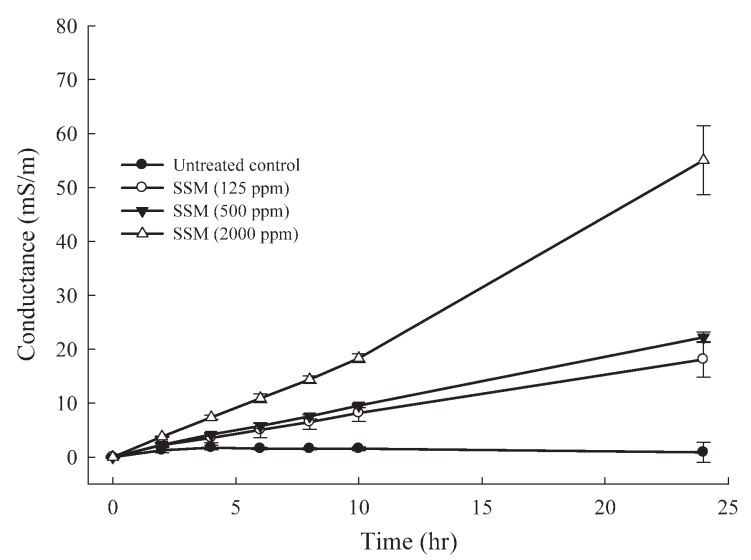

Fig. 4. Electrolyte leakage in Cucumis sativus by Streptomyces scopuliridis metabolites (SSM) at different concentration conditions.

tabacum induced by paraquat was similar to a report stating that leakage increased constantly (Mitsuko et al., 1995) and another report stating that $89 \%$ of electrolytes leaked in Avena fatua within 24 hours (Zhaohu et al., 2003). The SSM treated plant tissue released more opaque electrolytes leakage at 24 hours after treatment than that observed in the paraquat-treated or untreated control plant tissue. Electrolyte leakage induced by SSM at the concentration of 125 and 500 ppm increased gradually with time until 24 hours after treatment. At the concentration of 2,000 ppm of SSM, electrolyte leakage increased gradually until 10 hours after treatment but rapidly increased from 10 hours until 24 hours after treatment. The amount of electrolyte leakage induced by SSM at 500 ppm was not significantly different from that induced by SSM at $125 \mathrm{ppm}$. However, the amount of leakage at 2,000 ppm was approximately two times the amount observed following application at 125 and 500 ppm (Fig. 4). Accordingly, the amount of electrolyte leakage induced by SSM increased proportionally to the concentration of SSM until 24 hours after treatment but the increase was not as rapid as that induced by paraquat.

\section{Herbicidal symptoms and translocation of SSM}

Herbicidal symptoms and translocation of SSM from the middle of the second leaf were examined in $D$. ciliaris and $A$. theophrasti at the three leaf stage (Fig. 5). $D$. ciliaris showed discoloration on the SSM treated spot one day after treatment. D. ciliaris showed extended discoloration and twisting on the second leaf at 2 days after treatment; however, suppression by SSM downward direction in the second leaf was not observed, nor were there any signs of translocation of SSM to the first and third leaves through the phloem. Discoloration was also observed on the second leaf of $A$. theophrasti 3 days after treatment of SSM and extended upward through the xylem from the SSM treated spot. No sign of translocation SSM from the second leaf of $A$. theophrasti to other leaves was observed. Overall, the reaction induced by SSM was similar in both $D$. ciliaris and $A$. theophrasti and there was no translocation through the phloem to other leaves.

Taken together, these results indicate that SSM shows non-selective herbicidal activity and reaction speed equivalent to that of commercial herbicides. It is evident that the mode of action of SSM does not involve the inhibition of photosynthesis but the disruption of cell membranes. In addition, no translocation of SSM was observed in the plants. The results from this study suggest that SSM, which is a metabolite from a new strain of S. scopuliridis, could be a good candidate to become a broadspectrum contact herbicide.

A

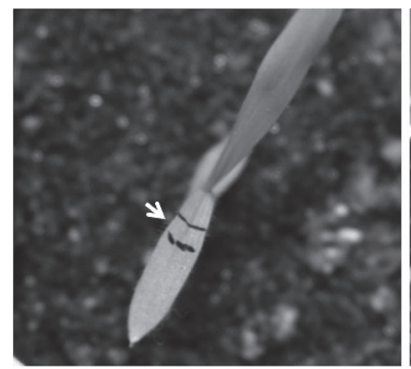

Untreated control

B

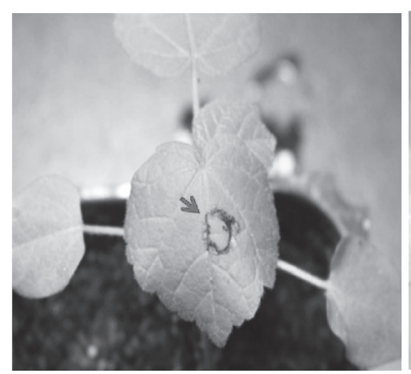

Untreated control

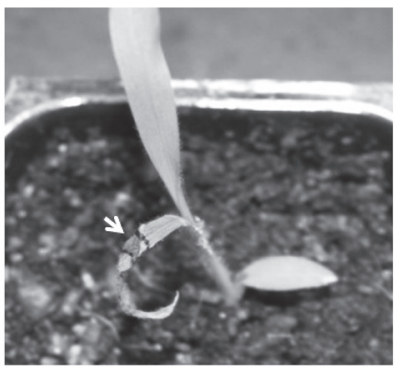

Streptomyces scopuliridis metabolites ( $4,000 \mathrm{ppm})$

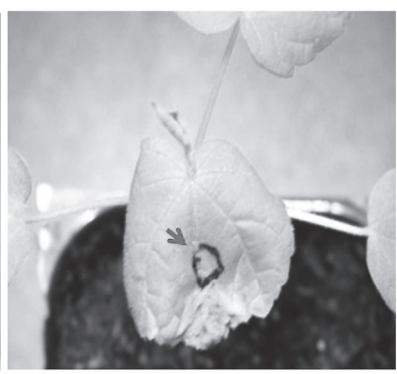

Streptomyces scopuliridis metabolites (SSM), $(4,000$
Fig. 5. Herbicidal symptoms and translocation of Streptomyces scopuliridis metabolites (SSM) in Digitaria ciliaris (A) and Abutilon theophrasti(B). 


\section{ACKNOWLEDGMENTS}

We would like to acknowledge the financial support from the R\&D Convergence Program of MSIP (Ministry of Science, ICT and Future Planning) and NST (National Research Council of Science \& Technology) of Republic of Korea (CCP-13-19-KRICT).

\section{REFERENCES}

Anderson W. P 1996 Weed science: principles and application (3rd rd.). West pub, New York, pp. 163-260

Arai M., T. Haneishi, N. Kitahara, R. Enikita, K. Kawakubo and Y. Kondo 1976 Herbicidins A and B, two new antibiotics with herbicidal activity. I. producing organism and biological activities. J. antibiot., 29: 863-869

Choi C. W., J. S. Choi, Y. K. Ko, C. J. Kim, Y. H. Kim, J. S. Oh, S. Y. Ryu and G. H. Yon 2014 (A)New Tricyclic Undecose Nucleoside from Streptomyces scopuliridis RB72. Bull. Korean Chem. Soc., 35(4): 1215-1217

Ebert E., K. H. Leist and D. Mayer 1990 Summary of safety evaluation toxicity studies of glufosinate ammonium. Food Chem. Toxicol., 28: 339-349

Fushimi S., S. Nishikawa, N. Mito, M. Ikemoto, M. Sasaki and H. Seto 1989 Studies on a new herbicidal antibiotic, homoalanosine. J. Antibiot., 42(9): 1370-1378

Iwai Y. and T. Takahashi 1992 Seletion of microbial sources of bioactive compounds. In "Search for Bioactive Compounds from Microorganisms" ed. by S. Omura, Springer-Verlag, New York, pp. 281-302

Joseph B., P. Sankarganesh, B. T. Edwin and S. J. Raj 2012 Endophytic Streptomycetes from plants with novel green chemistry: Review. Int. J. Biol. Chem., 6: 42-52

Kim J. C 2009 Trends of biocontrol agents. Biotechnology Policy Research Center, Bio-Special Zine., Vol. 10 (In Korean)

Lee H. B., C. J. Kim, J. S. Kim, K. S. Hong and K. Y. Cho 2003 A bleaching herbicidal activity of methoxyhygromycin (MHM) produced by an actinomycete strain Streptomyces sp. 8E-12. Lett. Appl. Microbiol., 36(6): 387-391
Lee Y. W 2007 Interpretation for reactive mechanism of 'glufosinate' using proteomics in oryza sativa. L. cv. lipumbyeo. Phd Diss, University of Seoul (In Korean)

Lee B. Y., J. D. Kim, Y. S. Kim, Y. K. Ko, G. H. Yon, C. J. Kim, S. J. Koo and J. S. Choi 2013 Identification of Streptomyces scopuliridis KR-001 and Its Herbicidal Characteristics. Weed Turf. Sci., 2(1): 38-46 (In Korean)

Li Z., V. K. Nandula and C. G. Messersmith 2003 Contact activity of difenzoquat differs from that of paraquat. Pest. Manng. Sci., 59: 928-932

Mitsuko A., S. Hikaru, F. Kousaku, S. Mamoru, K. Noriaki and T. Kiyoshi 1995 Decrease in Activity of Glutathione Reductase Enhances Paraquat Sensitivity in Transgenic Nkotiana tabacum. Plant Physiol., 107: 645-648

Nakajimam M., I. Kazuko, Y. Takamatsu, T. Kinoshita, T. Okazaki, K. Kawakubo, M. Shindo, T. Honma, M. Tohjigamori and T. Haneishi 1991 Hydantocidin : a new compound with herbicidal activity from Streptomyces hygroscopicus. J. Antibiot., 44(3): 293-300

Preston C., A. M. Joseph, M. Holtum and B. P. Stephen 1991 Resistance to the Herbicide Paraquat and Increased Tolerance to Photoinhibition Are Not Correlated in Several Weed Species. Plant Physiol., 96: 314-318

Omura S., M. Murata, H. Hanaki, K. Hinotozawa, R. Oiwa and H. Tanaka 1984 Phosalacine, a new herbicidal abtibiotic containing phosphinothricin. Fermentation, Isolation. Biological activity and Mechanism of action. J. Antibiot., 37: 829-835

Schatz A., E. Bugie and S, A. Waksman 1944 Streptomycin, a subastance exhibiting antibiotic activity against gram positive and gram negative bacteria. Proc. Soc. Exp. Biol. Med., 55 66-69

Sekizawa Y. and T. Takematsu 1982 How to discover antibiotics for herbicidal use. In "Abstracts of $5^{\text {th }}$ International Congress of pesticide Chemistry (IUPAC)", Kyoto, pp. 261-268

Tachibana K. and K. Kaneko 1986 Development of a new herbicide, bialaphos. J. of pestic. Sci., 11: 297-304

Umezawa H 1982 Trends in antibiotic research; Proceedings, an International Conference on Trends in Antibiotic Research; genetics, biosyntheses, actions \& new substances. Japan Antibiotics Research Association. Tokyo. Japan 